\title{
Thermal and mechanical properties of bio-based plasticizers mixtures on poly (vinyl chloride)
}

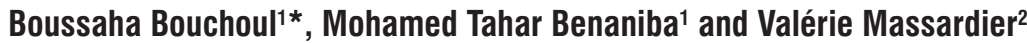

\begin{abstract}
'Laboratoire des Matériaux Polymérique MultiPhasiques - LMPMP, Département de Génie des Procédés, Faculté de Technologie, Université Sétif 1, Algérie

${ }^{2}$ Laboratoire Ingénierie des Matériaux Polymères UMR 5223, Centre National de la Recherche Scientifique - CNRS, Institut National des Sciences Appliquées de Lyon - INSA, Lyon, Villeurbanne, France

*B_Bouchoul@yahoo.com
\end{abstract}

\begin{abstract}
The use of mixtures of nontoxic and biodegradable plasticizers coming from natural resources is a good way to replace conventional phthalates plasticizers. In this study, two secondary plasticizers of epoxidized sunflower oil (ESO) and epoxidized sunflower oil methyl ester (ESOME) were synthesized and have been used with two commercially available biobased plasticizers; isosorbide diesters (ISB) and acetyl tributyl citrate (ATBC) in order to produce flexible PVC. Different mixtures of these plasticizers have been introduced in PVC formulations. Thermal, mechanical and morphological properties have been studied by using discoloration, thermogravimetric analysis (TGA), differential scanning calorimetry (DSC), dynamic mechanical thermal analysis (DMTA), tensile - strain and scanning electron microscopy (SEM). Studies have shown that PVC plasticization and stabilization were improved by addition of plasticizers blends containing ISB, ATBC, ESO and ESOME. An increase in the content of ESO or ESOME improved thermal and mechanical properties, whereas ESOME/ATBC formulations exhibited the best properties.
\end{abstract}

Keywords: PVC, epoxidized sunflower oil, epoxidized sunflower oil methyl ester, isosorbide diesters, acetyl tributyl citrate.

\section{Introduction}

Poly (vinyl chloride) (PVC) is very present in daily living applications due to its diverse properties and low $\operatorname{cost}^{[1,2]}$. Its properties depend on the amount of different kinds of additives such as plasticizers ${ }^{[3]}$. The plasticizer is a very important additive of PVC; it can improve the flexibility of PVC without changing its chemical properties ${ }^{[3-6]}$. Phthalates are the most commonly used plasticizers in PVC with applications in food packaging, medical devices, children's toys, building materials, and other common products ${ }^{[3]}$. Unfortunately, phthalates contaminate indoor environments, human food and are environmental contaminants. It has been reported by Bhakti et al. ${ }^{[3]}$ that several phthalates and especially diethyl hexyl phthalate (DEHP) also known as di-octyl phthalate (DOP) are suspected of having carcinogenic and toxic effects.

Recently, several alternatives exist to substitute DEHP in PVC applications ${ }^{[3]}$. Nowadays, there is an increasing interest in the use of nature based plasticizers for $\mathrm{PVC}^{[7,8]}$. Some studies have been done on the use of epoxidized sunflower oil (ESO) as secondary plasticizer to partially replace di-2-ehylhexyl phthalate (DEHP) in PVC formulations ${ }^{[9,10]}$. The compatibility of plasticizers with PVC also needs to be considered ${ }^{[1]]}$. Solubility parameters are often used to predict PVC/plasticizer interactions. Decrease in the glass transition temperature $\left(\mathrm{T}_{\mathrm{g}}\right)$ of PVC can also be studied to assess plasticization efficiency ${ }^{[12]}$.

Epoxidized sunflower oil (ESO) and epoxidized sunflower oil methyl esters (ESOME) were synthesized and then characterized by oxirane index titration and FTIR spectroscopy. The aim of the work reported here is to investigate the use of these new products as secondary plasticizers, mixed with isosorbide diesters (ISB) and acetyl tributyl citrate (ATBC) to plasticize PVC with 60 parts of plasticizers mixtures. The plasticization of PVC with ISB, as well as with its mixtures containing ESO and DEHP, has been studied in our previous work ${ }^{[13]}$. Although ATBC and ISB have been studied as individual plasticizers for this polymer ${ }^{[13,14]}$, ATBC, ISB and their mixtures with ESO or ESOME in $\mathrm{PVC}$ is the axis of the present research to evaluate thermal, mechanical and morphology characteristics of plasticized PVC. Discoloration degree of sheets, thermogravimetry analysis (TGA), dynamic mechanical thermal analysis (DMTA), differential scanning calorimetry (DSC), mechanical properties and scanning electron microscopy (SEM) were used to investigate the properties of our PVC plasticized with ATBC, ISB and their blends with ESO or ESOME.

\section{Materials and Methods}

\subsection{Materials}

PVC suspension grade resin (SE 950, K=65.7-67.1), was kindly supplied by Shintech (Houston, USA). Plasticizers used were as follows: acetyl tributyl citrate (ATBC) (Sigma Aldrich, USA), isosorbide diesters (ISB) (ID47, Roquette Frères, France), sunflower oil (SO) with an iodine value index, $\mathrm{I}_{\text {iod }}$, of $130 \mathrm{~g} \mathrm{I}_{2} / 100 \mathrm{~g}$ (Cevital Bejaia, Algeria), epoxidized sunflower oil (ESO) with $6.1 \%$ of oxirane oxygen $($ conversion $=98.2 \%$, yield $=80.5 \%$ ) and epoxidized sunflower oil methyl ester (ESOME), were prepared in our 
laboratory. $\mathrm{Ca} / \mathrm{Zn}$ stearates and stearic acid (SA) were used as thermal stabilizer and lubricant, respectively.

\subsection{Methods}

\subsubsection{Epoxidation of sunflower oil}

Sunflower oil (SO) and formic acid were combined in a $250 \mathrm{~mL}$ three neck flask equipped with stirrer, reflux condenser and thermocouple. The three neck flask was immersed in a heating mantle. Reaction occurred during mixing of the feed components and the reaction temperature was controlled at $55^{\circ} \mathrm{C}$. To start the epoxidation, hydrogen peroxide solution (30\%) was then added dropwise into the mixture for the first 30 minutes of reaction. The mole ratio of carbon double bonds to hydrogen peroxide $\left(\mathrm{C}=\mathrm{C}: \mathrm{H}_{2} \mathrm{O}_{2}\right)$ was 1: 1.5. After feeding $\mathrm{H}_{2} \mathrm{O}_{2}$ was completed, the reaction continued by mixing at a stirring speed of $700 \mathrm{rpm}$ and controlling the temperature at $55^{\circ} \mathrm{C}$ for a further two hours. After that, the product of reaction was next cooled and decanted for the separation of the organic soluble compounds (epoxidized oil) from the water soluble phase. The epoxidized sunflower oil (ESO) was then washed with warm water to remove residual contaminants. Diethyl ether was used to enhance the water separation ${ }^{[15]}$. The washed organic layer was also dried with centrifugation to remove water traces in the epoxidized oil. The epoxy functionality was determined using AOCS Cd 9-57 method ${ }^{[16]}$.

\subsubsection{Transesterification of epoxidized sunflower oil}

Reactions were performed in a $250 \mathrm{~mL}$ flat bottom glass vessel. Epoxidized sunflower oil was introduced to the glass vessel along with a magnetic stir bar. Sodium methoxide catalyst was dissolved in methanol and then added to the epoxidized sunflower oil in the reactor ${ }^{[17]}$. This mixture was heated to $50^{\circ} \mathrm{C}$ on a hot plate and magnetically stirred at $700 \mathrm{rpm}$. The reaction was stopped after 2 hours and the reaction mixture was transferred to a separatory funnel to recover the products. Then, the oxirane index is measured to confirm the no opening of oxirane cycles.

\subsubsection{Fourier transform infrared spectroscopy (FTIR)}

The samples were identified using Fourier transform infrared spectroscopy with a 680 Nicolet thermo spectrometer (Thermo Scientific, USA), employing an Attenuated Total Reflection (ATR) accessory, equipped with a diamond crystal cell, angle $45^{\circ}$. The spectra were acquired in the range $4000-500 \mathrm{~cm}^{-1}$ at a resolution of $4 \mathrm{~cm}^{-1}$ and the signal was averaged over 32 scans. Spectra were obtained by direct measurement.

\subsubsection{Preparation of PVC sheets}

The plasticized PVC sheets were prepared using PVC, ISB, ATBC, ESO and ESOME. Various combinations (on weight basis) were prepared and used as plasticizing mixtures. Four series of blends were prepared: $\mathrm{PVC} /(\mathrm{ISB} / \mathrm{ESO}$ ), $\mathrm{PVC} /(\mathrm{ISB} / \mathrm{ESOME}), \mathrm{PVC} /(\mathrm{ATBC} / \mathrm{ESO}), \mathrm{PVC} /(\mathrm{ATBC} / \mathrm{ESOME})$ and one formulation of PVC/DEHP as reference. In each case, 60 parts of this mixture was mixed with 100 parts of PVC. The different combinations used for the preparation of PVC sheets are displayed in Table 1.

Samples prepared with different plasticizer combinations were further mixed for 10 minutes by using a two roll mill at a temperature of $160^{\circ} \mathrm{C}$ to obtain a homogeneous blend.

\subsubsection{Discoloration sheets by static heat}

Circular test pieces (19 $\mathrm{mm}$ diameter) were placed in a circulating air oven maintained at $177 \pm 2{ }^{\circ} \mathrm{C}$. Test pieces were removed at intervals of $5,10,15,20,30,45,60,80$, $100,130,160$ and 200 minutes. The color changes with the heating time were observed and measured with color Synmero scale as described by Ocskay et al. ${ }^{[18]}$.

\subsubsection{Thermogravimetry analysis (TGA)}

Thermal degradation studies were conducted using a thermogravimetry analyzer TGA (Q500 TA Instruments, USA). All the samples were evaluated from ambient to $500^{\circ} \mathrm{C}$ under nitrogen flow $(40 \mathrm{~mL} / \mathrm{min})$ at $10^{\circ} \mathrm{C} / \mathrm{min}$ heating rate.

\subsubsection{Differential scanning calorimetry (DSC)}

Glass transition temperature $\left(\mathrm{T}_{\mathrm{g}}\right)$ was determined by differential scanning calorimetry using a DSC Q10 (TA Instruments, USA) calibrated with indium. Samples of about $8 \mathrm{mg}$ were conditioned in aluminum pans, equilibrated at $25^{\circ} \mathrm{C}$ and held isothermally for $1 \mathrm{~min}$. Then, they were heated to $220^{\circ} \mathrm{C}$ at $20^{\circ} \mathrm{C} / \mathrm{min}$ and held isothermally for $3 \mathrm{~min}$ at $220^{\circ} \mathrm{C}$ to eliminate previous thermal history. The samples were then cooled to $-60^{\circ} \mathrm{C}$ and held isothermally for $3 \mathrm{~min}$ and finally heated to $220^{\circ} \mathrm{C}$ at a constant rate of $10^{\circ} \mathrm{C} / \mathrm{min}$.

\subsubsection{Dynamic mechanical thermal analysis (DMTA)}

All tests were conducted with RSA Rheometrics. The analyses were carried out on specimens measuring $30 \times 7 \times 0.5 \mathrm{~mm}^{3}$ in tensile mode with a temperature ranging from $-60^{\circ} \mathrm{C}$ to $80^{\circ} \mathrm{C}$ at a $3^{\circ} \mathrm{C} / \mathrm{min}$ heating rate with frequency

Table 1. Compositions of our plasticized formulations.

\begin{tabular}{|c|c|c|c|c|c|c|c|c|c|c|c|c|c|c|}
\hline \multirow{2}{*}{$\begin{array}{c}\text { Materials } \\
(\mathbf{p h r})\end{array}$} & \multicolumn{14}{|c|}{ Formulation number } \\
\hline & 1 & 2 & 3 & 4 & 5 & 6 & 7 & 8 & 9 & 10 & 11 & 12 & 13 & 14 \\
\hline $\mathrm{PVC}$ & 100 & 100 & 100 & 100 & 100 & 100 & 100 & 100 & 100 & 100 & 100 & 100 & 100 & 100 \\
\hline SA & 1 & 1 & 1 & 1 & 1 & 1 & 1 & 1 & 1 & 1 & 1 & 1 & 1 & 1 \\
\hline $\mathrm{Ca} / \mathrm{Zn}$ & 2 & 2 & 2 & 2 & 2 & 2 & 2 & 2 & 2 & 2 & 2 & 2 & 2 & 2 \\
\hline ISB & 60 & 50 & 40 & 30 & - & - & - & - & 50 & 40 & 30 & - & - & - \\
\hline ATBC & - & - & - & - & 60 & 50 & 40 & 30 & - & - & - & 50 & 40 & 30 \\
\hline ESO & - & 10 & 20 & 30 & - & 10 & 20 & 30 & - & - & - & - & - & - \\
\hline ESOME & - & - & - & - & - & - & - & - & 10 & 20 & 30 & 10 & 20 & 30 \\
\hline
\end{tabular}


of $1,3,5$ or $10 \mathrm{~Hz}$. $\mathrm{T}_{\alpha}$ was taken at the peak in the $\tan \delta$ curve accompanied by a step reduction in the storage modulus.

\subsubsection{Mechanical properties}

Test specimens were cut according to NF T 51-034 H1. The Young's modulus, tensile strength and elongation at break were determined at room temperature with a universal dynamometer (Instron, ref. 33R4469, USA) at constant rate of $50 \mathrm{~mm} / \mathrm{min}$ by using a $0.5 \mathrm{kN}$ sensor.

\subsubsection{Scanning electron microscopy (SEM)}

Morphological studies were conducted using a scanning electron microscope JEOL (model JFM-6360 LV). Specimens were sputter-coated with gold to a thickness of $10 \mathrm{~nm}$ before surface characterization to prevent charging. The SEM was equipped with a lanthanum hexaboride (LaB6) crystal as electron emitter source. An accelerating voltage of $13 \mathrm{kV}$ was used to collect the SEM images.

\section{Results and Discussion}

\subsection{Epoxidation of sunflower oil (ESO)}

There are two main reactions involved in the epoxidation reaction as mentioned above. During the first stage, peroxy acid is formed from the reaction of formic acid and hydrogen peroxide while, in a second stage, epoxidized sunflower oil is produced from the reaction between peracid and double bonds in the sunflower oil ${ }^{[19]}$.

The following reaction scheme considers hydrogen peroxide as oxygen donor and acetic acid as oxygen carrier ${ }^{[20]}$ :

Step 1: Formation of Peroxy formic acid

$$
\mathrm{CH}_{3} \mathrm{COOH}+\mathrm{H}_{2} \mathrm{O}_{2} \rightleftharpoons \mathrm{CH}_{3} \mathrm{COOOH}+\mathrm{H}_{2} \mathrm{O}
$$

Step 2: Epoxidation Reaction

$$
-\mathrm{CH}_{2}=\mathrm{CH}_{2^{-}}+\mathrm{CH}_{3} \mathrm{COOOH} \longrightarrow-\mathrm{HC}-\mathrm{CH}-+\mathrm{CH}_{3} \mathrm{COOH}
$$

\subsection{Transesterification of epoxidized sunflower oil}

In the transesterification, ESO reacts with methanol in the presence of $\mathrm{NaOH}$, and produces a mixture of epoxidized fatty acids alkyl esters and glycerol (Scheme 1).
Schuchardt et al. ${ }^{[21]}$. have reported that the overall process is a sequence of three consecutive and reversible reactions, in which di and monoglycerides are formed as intermediates. The stoichiometric reaction requires $1 \mathrm{~mol}$ of ESO and $3 \mathrm{~mol}$ of methanol. However, an excess of alcohol is used to increase the yields of epoxidized alkyl esters and to allow its phase separation from the glycerol formed ${ }^{[21]}$.

\subsection{Fourier transform infrared spectroscopy (FTIR)}

Products were characterized by FTIR (Figure 1) in order to follow the disappearance of double bonds and formation of epoxy groups. For $\mathrm{SO}$, the characteristic peaks at $3008.44 \mathrm{~cm}^{-1}$ and $723.95 \mathrm{~cm}^{-1}$ are attributed to the stretching vibration of the double bonds $=\mathrm{C}-\mathrm{H}_{2}$ and $-\mathrm{CH}=\mathrm{CH}-$, respectively. The FTIR spectrum displays peaks of ESO at $863.58 \mathrm{~cm}^{-1}$ and of ESOME at $845.30 \mathrm{~cm}^{-1}$, characteristic of the C-O-C oxirane stretch and disappearance of the double bond at $3008.44 \mathrm{~cm}^{-1}$. It indicates the almost complete conversion of $\mathrm{C}=\mathrm{C}$ unsaturations to epoxy groups and confirms the success of the epoxidation reaction of $\mathrm{ESO}^{[22,23]}$ on fatty acid chains.

The other new peaks at $3373.35 \mathrm{~cm}^{-1}$ for ESO and at $3374.51 \mathrm{~cm}^{-1}$ for ESOME are attributed to the hydroxyl functional group, derived from the epoxy functional group via partial epoxy ring opening reaction. The epoxy ring opening reaction could occur either by acid catalysis in the presence of water

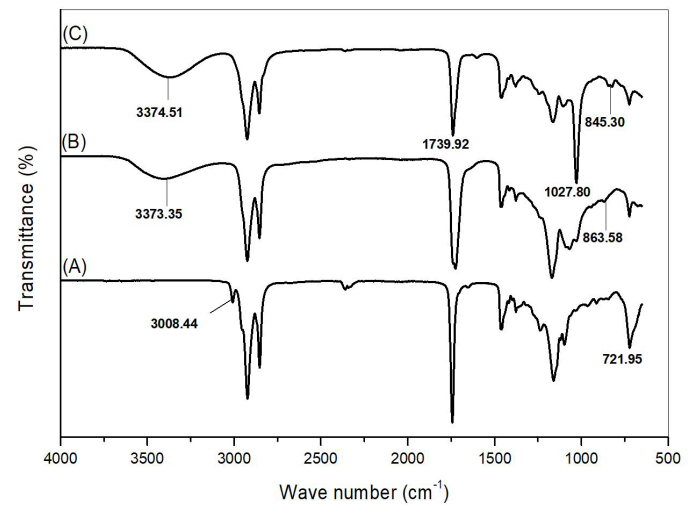

Figure 1. FTIR of (A) SO; (B) ESO and (C) ESOME.

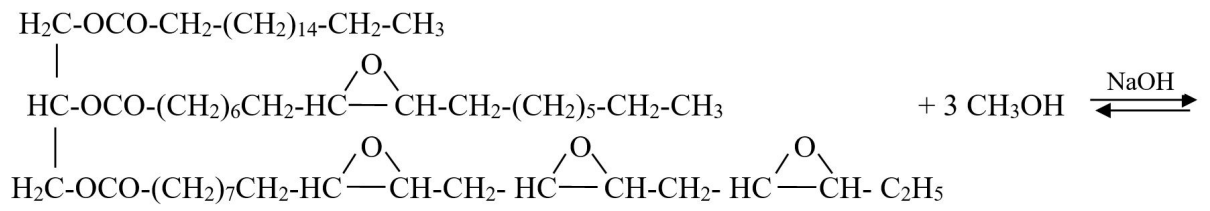

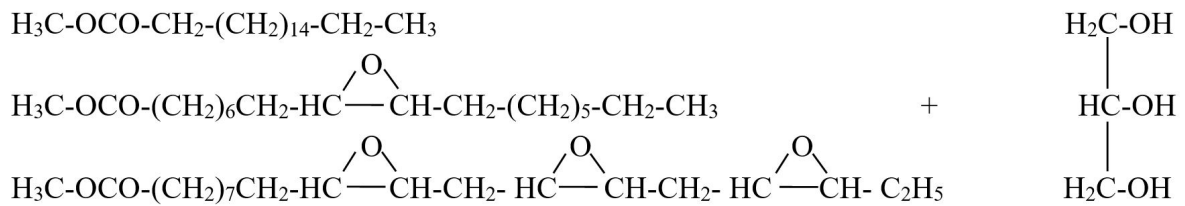

Scheme 1. Reaction for the synthesis of ESOME from ESO. 

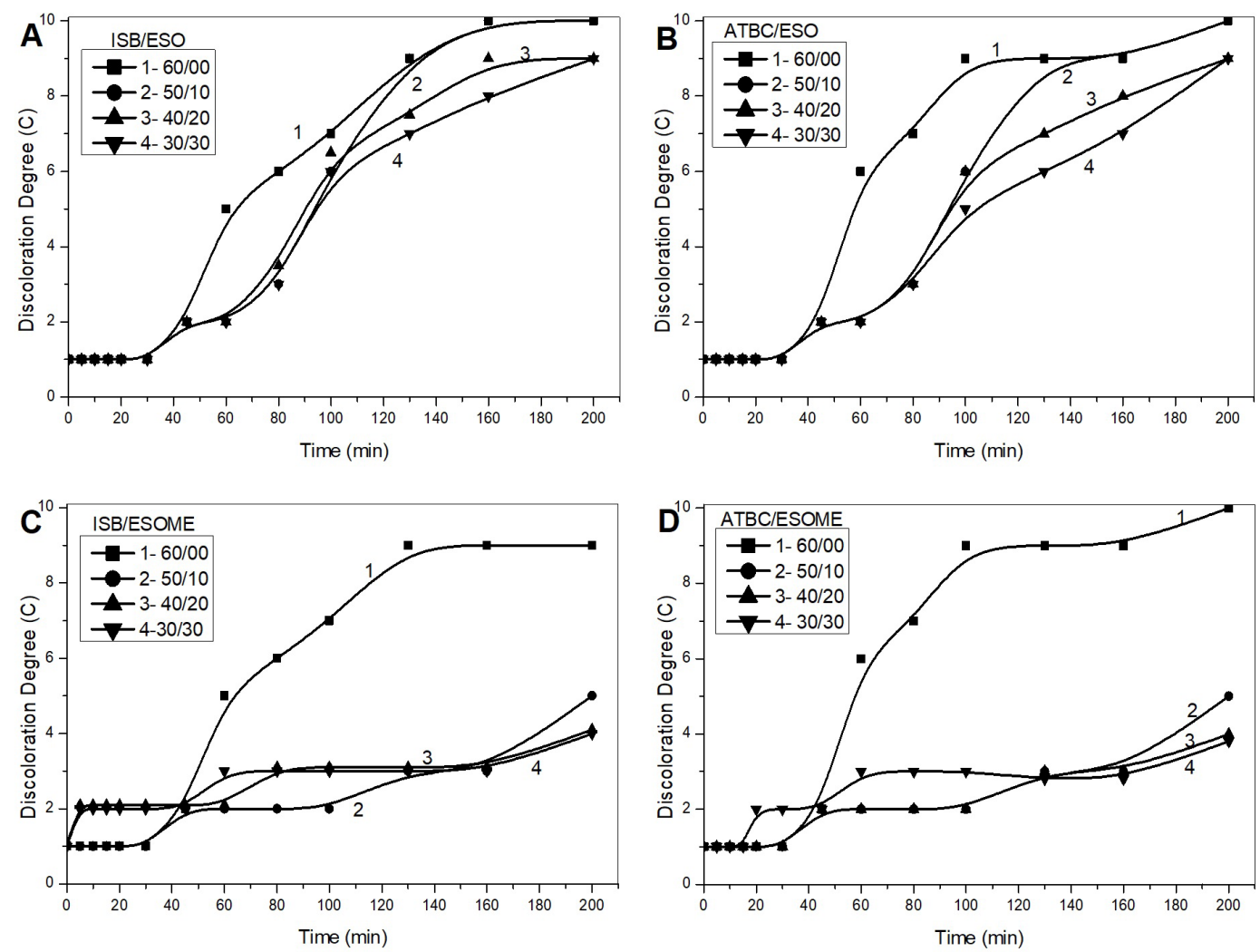

Figure 2. Discoloration degree of plasticized PVC films with: (A) ISB/ESO; (B) ATBC/ESO; (C) ISB/ESOME; (D) ATBC/ESOME.

associated with aqueous solution of $\mathrm{H}_{2} \mathrm{O}_{2}$ used ${ }^{[15]}$. The peak in the spectrum of ESOME at $1739.92 \mathrm{~cm}^{-1}$ indicates the shifting of $\mathrm{C}=\mathrm{O}$ absorption band and the characteristic ester band at $1027.80 \mathrm{~cm}^{-1}$, these results indicate that the functional group has been converted into-COOC- for the three ester functions ${ }^{[23,24]}$.

\subsection{Discoloration sheets by static heat}

A study of coloration change is an important method for investigating the stabilizing performance of plasticizers in PVC when the variation of the PVC color from transparency towards yellow to brown then black, indicate the evolution of the degradation state of PVC sheets.

The discoloration degree of PVC samples before and after degradation was determined by using the Synmero scale. The samples are colored because of the dehydrochlorination and formation of conjugated double bonds in PVC sheets. During dehydrochlorination, $\mathrm{HCl}$ molecules are extracted, which initiates the formation of double bonds and polyenes in PVC chains and noticeable color change from yellow to black, when the conjugated polyene sequences contain more than four to five double bonds ${ }^{[25]}$. Figure 2 shows the discoloration degree of sheets containing different mixtures of plasticizers. All sheets turn brownish with discoloration degree $(\mathrm{C} \approx 5)$ after 40 min.

The sheets containing ISB and ATBC alone were blackening after 120 minutes. But the dispersion of ESO, the degree of discoloration decreases by increasing the rate of ESO, either mixed with ISB (Figure 2A) or with ATBC (Figure 2B) in the plasticizer system. In the case of ESOME, (Figure 2C) and (Figure 2D), the sheets have a yellow color for times in the range [0-200 minutes].

This yellowish appearance could be related to polyene formation due to dehydrochlorination of PVC with the reaction of $\mathrm{HCl}$ and $\mathrm{ESOME}^{[26]}$. Thus, the combination of ESO and ESOME with ISB or ATBC increases the thermal stability of formulations compared with samples containing ISB or ATBC alone. The changes in discoloration degrees for the PVC were minimal in the films plasticized in presence of ESO or ESOME. Epoxy groups of ESO and ESOME neutralize the $\mathrm{HCl}$ evolved by dehydrochlorination of PVC. Thus, auto acceleration of dehydrochlorination by evolved $\mathrm{HCl}$ is prevented because it is captured by epoxy groups, owing epoxy groups in ESO and ESOME to react with $\mathrm{HCl}$, generated from $\mathrm{PVC}^{[27]}$, as shown in reaction 3.<smiles>CC1(C)OC1(C)C</smiles>

\subsection{Thermogravimetry analysis}

Figure 3 shows the TGA and DTG curves of plasticized PVC by some plasticizer blends. The curves have similar shapes for all formulations and each one presents two distinct stages. 
Table 2 summarizes the thermal performance data of plasticized PVC by the different systems in the first and second stage respectively.

The characteristical thermal parameters selected were the $1 \%$ weight loss (T $1 \%$ ), which is the initial weight loss temperature, maximum degradation temperature ( $\mathrm{T}_{1}$ max and $\left.\mathrm{T}_{2} \max \right)$, which is the highest thermal degradation rate temperature obtained from the peak of weight loss, maximum speed of degradation $\left(\mathrm{S}_{1} \max\right.$ and $\left.\mathrm{S}_{2} \max \right)$, the $5 \%$ weight loss (T 5\%), the 50\% weight loss (T 50\%) and the residue. The elimination of a large amount of $\mathrm{HCl}$ happened at about $200^{\circ} \mathrm{C}$. It could be attributed to the first thermal degradation stage. The second stage above $400^{\circ} \mathrm{C}$ is attributed to crosslinking of chains containing $\mathrm{C}=\mathrm{C}$ bonds as the process of thermal degradation of polyenes involves cyclization and splitting of chains ${ }^{[8]}$. The results obtained in this range show that the PVC mixed with ATBC begins to lose weight at a lower temperature than that with ISB. However, formulations with ESO (formulation number 4,8) or with ESOME (formulation number 11, 14) present the minimal weight loss in the first step.
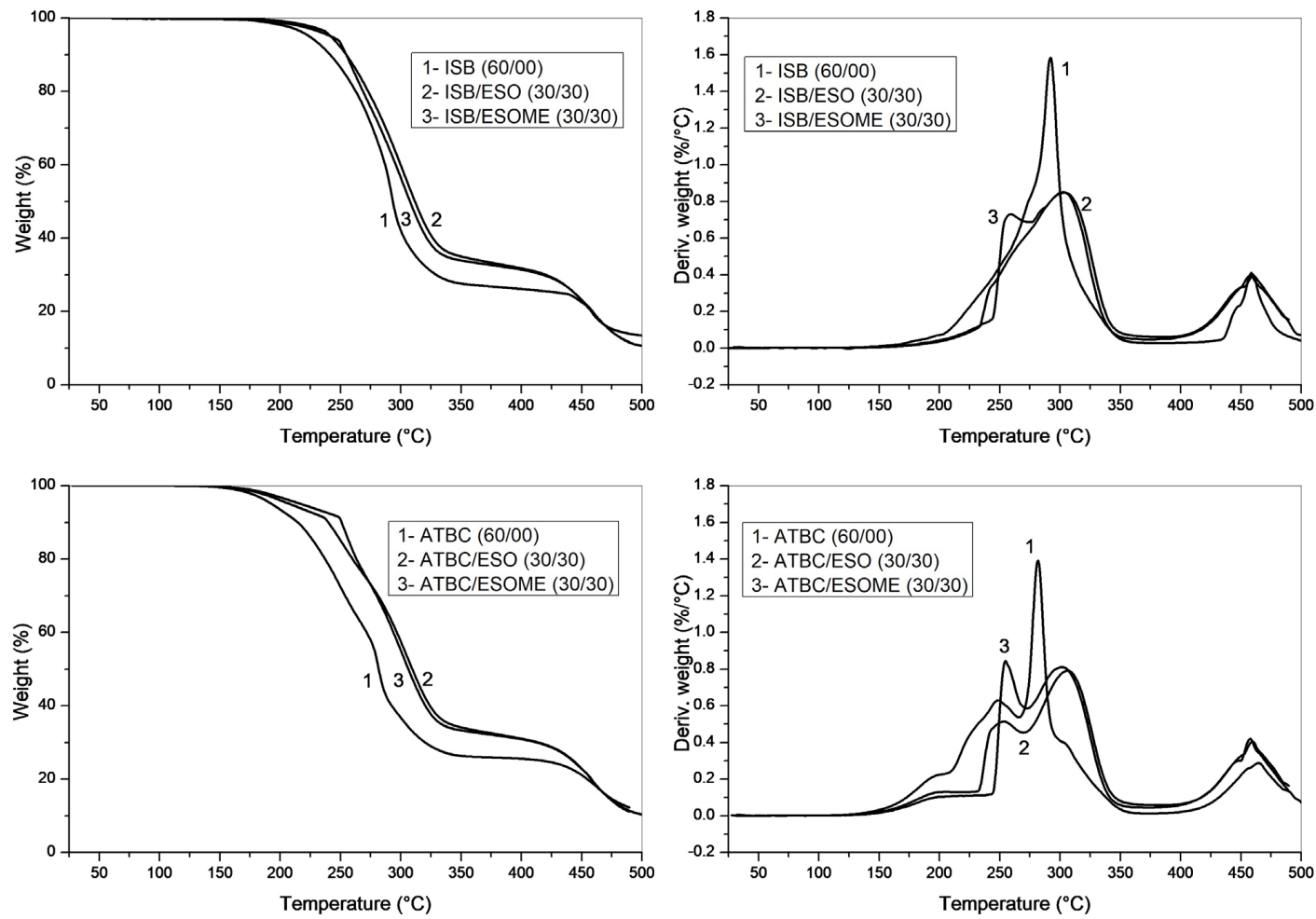

Figure 3. TGA and DTG curves for PVC plasticized with ISB, ATBC and their blends with 30 phr of ESO and ESOME.

Table 2. Thermal gravimetric analysis (TGA) results of the formulations.

\begin{tabular}{|c|c|c|c|c|c|c|c|c|c|}
\hline \multirow[b]{2}{*}{$\begin{array}{c}\text { Formulation } \\
\text { number }\end{array}$} & \multicolumn{6}{|c|}{ First stage } & \multicolumn{3}{|c|}{ Second stage } \\
\hline & $\mathrm{T} 1 \%\left({ }^{\circ} \mathrm{C}\right)$ & $\begin{array}{c}\mathrm{T}_{1} \max \\
\left({ }^{\circ} \mathrm{C}\right)\end{array}$ & $\begin{array}{l}\mathrm{S}_{1} \max \\
\left(\% /{ }^{\circ} \mathrm{C}\right)\end{array}$ & T $5 \%\left({ }^{\circ} \mathrm{C}\right)$ & $\begin{array}{c}\text { T } 50 \% \\
\left({ }^{\circ} \mathrm{C}\right)\end{array}$ & $\begin{array}{l}\text { Weight loss } \\
(\%)\end{array}$ & $\begin{array}{c}\mathrm{T}_{2} \max \\
\left({ }^{\circ} \mathrm{C}\right)\end{array}$ & $\begin{array}{l}\mathrm{S}_{2} \max \\
\left(\% /{ }^{\circ} \mathrm{C}\right)\end{array}$ & $\begin{array}{c}\text { Residue } \\
\text { at } 480{ }^{\circ} \mathrm{C} \\
(\%)\end{array}$ \\
\hline 1 & 184.0 & 292.2 & 1.58 & 224.2 & 293.4 & 73.4 & 458.7 & 0.41 & 13.8 \\
\hline 2 & 193.1 & 293.4 & 1.12 & 230.7 & 297.5 & 72.1 & 459.3 & 0.35 & 11.0 \\
\hline 3 & 196.9 & 297.6 & 0.84 & 235.6 & 304.1 & 69.0 & 459.7 & 0.38 & 11.3 \\
\hline 4 & 204.0 & 302.8 & 0.85 & 241.9 & 311.6 & 67.0 & 457.3 & 0.39 & 11.6 \\
\hline 5 & 160.9 & 281.8 & 1.39 & 193.0 & 281.8 & 74.1 & 465.4 & 0.29 & 12.3 \\
\hline 6 & 165.4 & 284.7 & 0.87 & 198.8 & 290.5 & 72.2 & 461.1 & 0.34 & 10.9 \\
\hline 7 & 165.8 & 303.3 & 0.75 & 201.4 & 303.4 & 69.0 & 460.7 & 0.37 & 11.2 \\
\hline 8 & 168.9 & 305.7 & 0.79 & 208.0 & 309.4 & 67.2 & 459.2 & 0.40 & 11.1 \\
\hline 9 & 196.0 & 292.4 & 1.18 & 231.6 & 296.5 & 72.3 & 459.9 & 0.33 & 10.8 \\
\hline 10 & 197.8 & 295.5 & 0.95 & 237.0 & 301.8 & 69.5 & 460.1 & 0.37 & 11.1 \\
\hline 11 & 198.0 & 302.0 & 0.85 & 242.1 & 307.5 & 67.0 & 460.4 & 0.39 & 11.3 \\
\hline 12 & 164.3 & 285.4 & 1.00 & 196.8 & 288.5 & 73.0 & 459.8 & 0.35 & 9.9 \\
\hline 13 & 167.0 & 252.1 & 0.90 & 203.9 & 300.8 & 69.5 & 461.0 & 0.38 & 11.2 \\
\hline 14 & 172.3 & 254.4 & 0.84 & 217.2 & 306.1 & 67.7 & 457.5 & 0.42 & 11.2 \\
\hline
\end{tabular}


In the first step, the presence of $30 \mathrm{phr}$ ESO or ESOME with $30 \mathrm{phr}$ ISB or with 30phr ATBC Instead of $60 \mathrm{phr}$ ISB or $60 \mathrm{phr}$ ATBC retards the temperature at $5 \%$ weight loss from respectively $224.2^{\circ} \mathrm{C}$ and $193.0^{\circ} \mathrm{C}$ to $241.9^{\circ} \mathrm{C}$ and $208.0^{\circ} \mathrm{C}$ and decreases the weight loss from $73.4 \%$ and $74.1 \%$ to $67.0 \%$ and $67.2 \%$ respectively. These results are in agreement with those of Joseph et al. ${ }^{[28]}$. From Table 2, it could be observed that the value of $\mathrm{T}_{1}$ max increases with the addition of ESO or ESOME in the plasticizer system. On the other hand, $\mathrm{S}_{1}$ max decreases.

The second stage of the degradation begins at temperatures higher than $400^{\circ} \mathrm{C}$. Thermal degradation of the polyene sequences occurring during this stage yields volatile aromatic and aliphatic compounds by the intermolecular cyclization of the conjugated sequences ${ }^{[13]}$.

However, the second degradation stage occurs without any marked variation in the temperature range. Hence, ESO and ESOME improve the thermal stability of PVC blends better than ISB or ATBC.

\subsection{Differential scanning calorimetry (DSC)}

The glass transition temperature $(\mathrm{Tg})$ of all the sheets with various plasticizer combinations was determined by using differential scanning calorimetry (DSC).

This temperature is an important parameter in polymer characterization to evaluate the plasticizing effect of plasticizers mixtures added to polymer systems. DSC curves of the realized formulations are displayed in Figure 4.

The analyzed plasticized PVC sheets show Tg values ranging between $62.1^{\circ} \mathrm{C}$ and $65.5^{\circ} \mathrm{C}$. Unplasticized PVC exhibits a glass transition temperature $(\mathrm{Tg})$ at $81.0^{\circ} \mathrm{C}$. We have observed that with incorporation of plasticizers systems, $\mathrm{Tg}$ values decrease steadily down to $65^{\circ} \mathrm{C}$. This indicates the excellent plasticizing effect of plasticizers mixtures for $60 \mathrm{phr}$ by weight ${ }^{[29]}$.

The data displayed in Figure 4 indicates that $\mathrm{Tg}$ values evolve slightly with ISB or ATBC and when ESO or ESOME quantity is increased from 10 to $30 \mathrm{phr}$ in plasticizer system, which is agreement with a good miscibility of ISB, ATBC, ESO and ESOME with PVC.

A low value is observed for the ATBC alone $\left(65.5^{\circ} \mathrm{C}\right)$ but it even decreases by addition of ESO or ESOME at $30 \mathrm{phr}$ to $63.6^{\circ} \mathrm{C}$ and $64.6^{\circ} \mathrm{C}$ respectively. Another low value is obtained for ISB alone $\left(62.1^{\circ} \mathrm{C}\right)$ and it increases slightly by adding ESO and ESOME from $10 \mathrm{phr}$ to $20 \mathrm{phr}$. These data observations suggest that the length of the alkoxy group plays a critical role in controlling the available free volume, as it has been reported by Stuart et al. ${ }^{[29]}$.

\subsection{Dynamic mechanical thermal analysis (DMTA)}

DMTA was used to investigate the compatibility of the plasticizers with PVC. Generally, for an immiscible blend, the $\tan \delta$ curve shows a large peak. For a highly compatible plasticizer system, the curve shows a narrow peak ${ }^{[14,30]} \cdot \tan \delta$, loss modulus (E") and FWHM (full width at half maximum) ${ }^{[31]}$ of realized formulations are displayed in Table 3 .

The DMTA data indicate that the T $\alpha$ peak shifts to lower temperature when increasing concentrations of ISB or ATBC in the plasticized blends (Figure 5). Based on the data in Table 3, for example, the T $\alpha$ peak for the ISB/ESO system decreases from $23.0^{\circ} \mathrm{C}$ to $11.4^{\circ} \mathrm{C}$ when the ISB concentration increases from 30 to $60 \mathrm{phr}$ respectively. The variation of $\mathrm{T}_{\alpha}$ is a very important factor in the evaluation of the
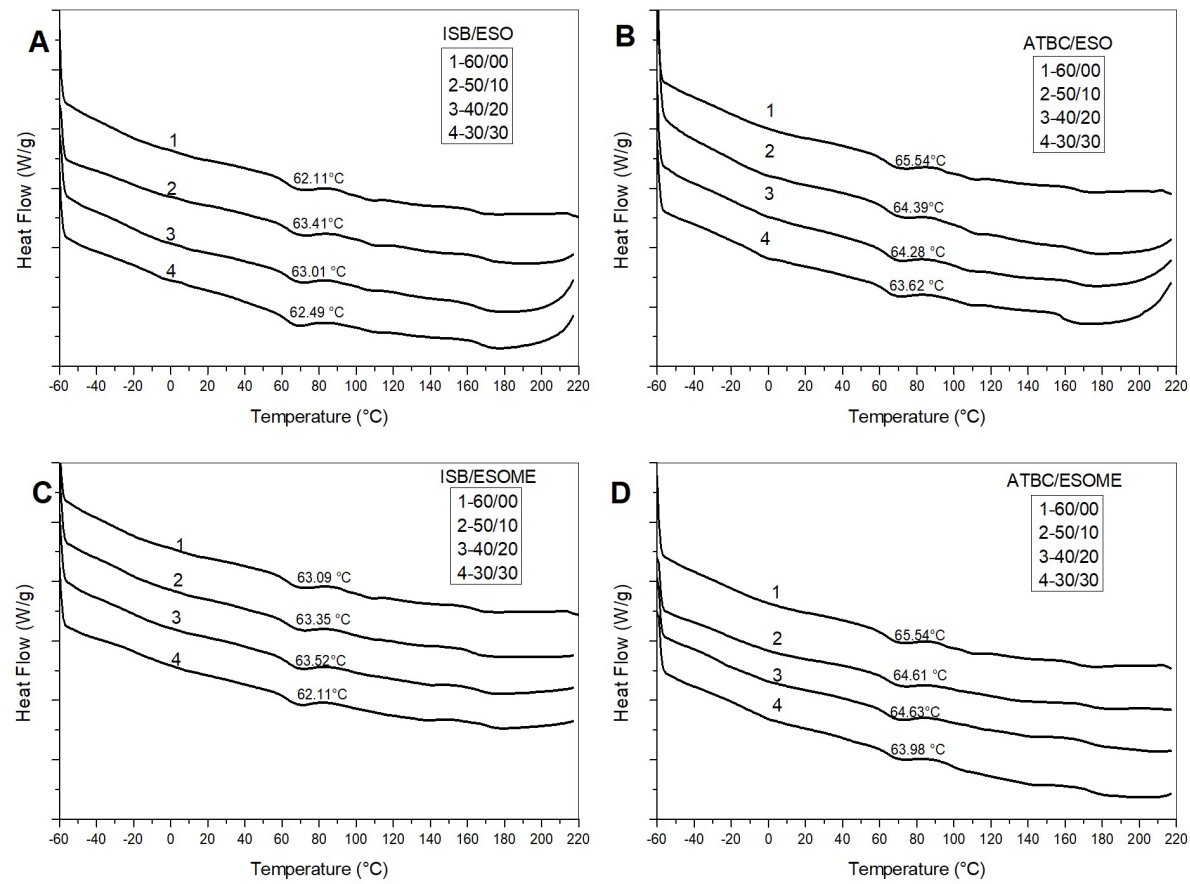

Figure 4. DSC curves of plasticized PVC films with: (A) ISB/ESO; (B) ATBC/ESO; (C) ISB/ESOME; (D) ATBC/ESOME. 
Table 3. DMTA analysis of T drawn from E" peak $\left({ }^{\circ} \mathrm{C}\right), \mathrm{FWHM}\left({ }^{\circ} \mathrm{C}\right), \mathrm{T} \alpha$ at different frequencies and the activation energy of PVC films with mixtures of plasticizers.

\begin{tabular}{|c|c|c|c|c|c|c|c|}
\hline \multirow{2}{*}{$\begin{array}{c}\text { Formulation } \\
\text { Number }\end{array}$} & \multirow{2}{*}{$\begin{array}{c}\text { T from } E^{\prime \prime}\left({ }^{\circ} \mathrm{C}\right) \\
1 \mathrm{~Hz}\end{array}$} & \multirow{2}{*}{$\begin{array}{c}\text { FWHM }\left({ }^{\circ} \mathrm{C}\right) \\
1 \mathrm{~Hz}\end{array}$} & \multicolumn{4}{|c|}{$\mathrm{T} \alpha\left({ }^{\circ} \mathrm{C}\right)$} & \multirow{2}{*}{$\begin{array}{l}\text { Activation } \\
\text { Energy Ea } \\
{\text { kcal. } \text { mol }^{-1}}\end{array}$} \\
\hline & & & $1 \mathrm{~Hz}$ & $3 \mathrm{~Hz}$ & $5 \mathrm{~Hz}$ & $10 \mathrm{~Hz}$ & \\
\hline 1 & -30.6 & 51.6 & 11.4 & 15.6 & 18.4 & 19.0 & 45.02 \\
\hline 2 & -28.9 & 52.7 & 18.3 & - & - & - & - \\
\hline 3 & -27.1 & 58.5 & 21.7 & - & - & - & - \\
\hline 4 & -23.3 & 60.6 & 23.0 & 31.6 & 33.5 & 35.7 & 30.88 \\
\hline 5 & -33.8 & 45.1 & 6.8 & 12.7 & 13.7 & 15.9 & 39.10 \\
\hline 6 & -31.6 & 48.9 & 10.2 & - & - & - & - \\
\hline 7 & -29.7 & 53.0 & 17.2 & - & - & - & - \\
\hline 8 & -25.8 & 54.8 & 21.6 & 27.5 & 30.9 & 35.0 & 30.50 \\
\hline 9 & -27.1 & 52.7 & 14.1 & - & - & - & - \\
\hline 10 & -24.1 & 53.0 & 19.9 & - & - & - & - \\
\hline 11 & -22.0 & 56.8 & 23.4 & 28.7 & 30.3 & 35.3 & 35.70 \\
\hline 12 & -32.9 & 47.3 & 11.1 & - & - & - & - \\
\hline 13 & -30.8 & 47.4 & 15.0 & - & - & - & - \\
\hline 14 & -17.2 & 49.4 & 19.5 & 23.1 & 24.7 & 28.3 & 46.57 \\
\hline
\end{tabular}

FWHM: Full width at half maximum.
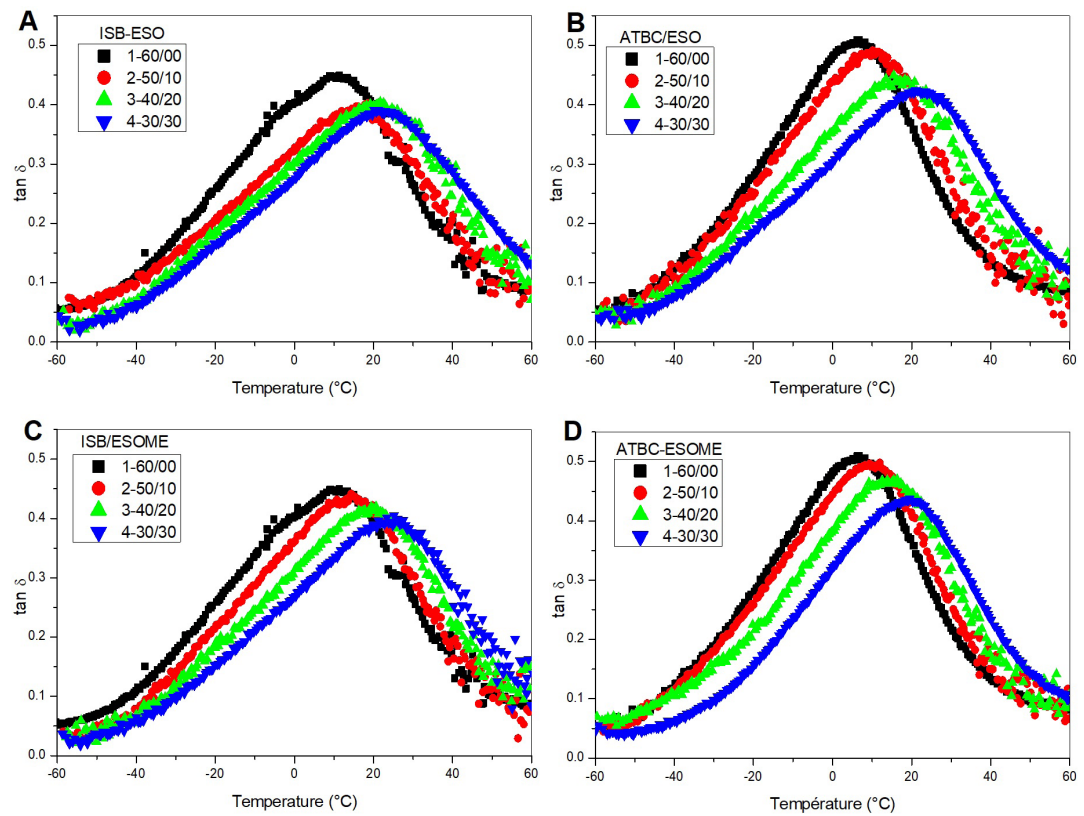

Figure 5. $\tan \delta$ peaks of PVC films plasticized with various plasticizers mixture (A) ISB/ESO; (B) ATBC/ESO; (C) ISB/ESOME; (D) ATBC/ESOME.

plasticizer effect and it can be seen that the T $\alpha$ values of formulations with $60 \mathrm{phr}$ ISB or $60 \mathrm{phr}$ ATBC are $11.4^{\circ} \mathrm{C}$ and $6.8^{\circ} \mathrm{C}$, respectively.

This means that all the plasticizers mixtures show good plasticization of PVC. The T $\alpha$ values with $60 \mathrm{phr}$ ATBC or 60 phr DOP (not shown) based formulations are very close with little difference on each other $\left(1.8^{\circ} \mathrm{C}\right)$. However, it is known that DOP is dangerous for human health $^{[30]}$, so ATBC is a potentially less toxic plasticizer for PVC based compositions. Table 3 shows that the FWHM values of PVC with ATBC and ISB alone are smaller than the FWHM values of plasticized systems with ESO and
ESOME secondary plasticizers. When ISB and ATBC content increases in plasticizer systems, the FWHM values decrease; this indicates the good compatibility of ISB and ATBC with PVC.

From the frequency dependence of the $\mathrm{T} \alpha$, the values of activation energy for the plasticized samples are calculated (Table 3). It appears that there is a dependence of the activation energy on the measured $\mathrm{T} \alpha$. It can be related to the good compatibility between PVC with ISB/ESO, ATBC/ESO and ISB/ESOME. The points corresponding to the plasticized PVC samples are shifted toward lower values of activation energy ${ }^{[9]}$. 

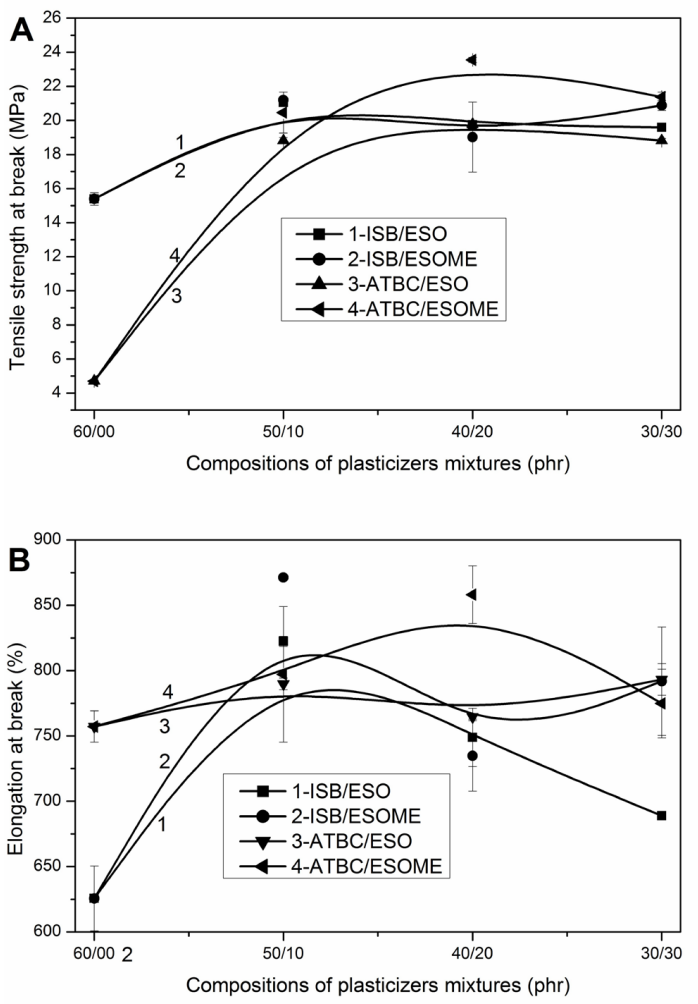

Figure 6. Mechanical properties of plasticized PVC films: (A) Tensile strength (Mpa); (B) Elongation at break (\%).

\subsection{Mechanical properties}

Figure 6 shows the effect of the plasticizers compositions on tensile strength and elongation at break of PVC formulations. The tensile strength decreases by rising the amount of ISB or ATBC in the plasticizers systems, whereas the elongation at break increases with a rise in content of ESO and ESOME from 0 to $20 \mathrm{phr}$ in plasticizer systems. The increase in tensile strength and decrease in elongation at break with $30 \mathrm{phr}$ of ESO or ESOME in plasticizers systems is attributed to the increased polarity of the plasticizer, which growths the cohesive energy density (intensity of intermolecular attractions), so that with a higher polarity, materials tend to hold themselves together more tightly ${ }^{[32]}$. As a result, the chain mobility and thus the flexibility of the compounds are reduced, although the increase in tensile strength and decrease in elongation at break with ESO plasticizer may be attributed to its high viscosity. Reduction in tensile strength with an increase in ATBC or ISB content ( $60 \mathrm{phr}$ ) possibly result from a high plasticization efficiency compared to the one of other plasticizers ${ }^{[33]}$, which allows facile sliding of polymer chains past each other ${ }^{[32]}$. Hence, compounds of ATBC/ESOME (40/20) and ISB/ESOME (50/10) give the highest elongation at break $858 \%$ and $871 \%$ respectively.

\subsection{Scanning electron microscopy (SEM)}

Fractured surfaces of the selected formulations were investigated by SEM. The microscopic structures of PVC films plasticized with different plasticizers mixtures are displayed in Figure 7. A homogeneous and regular aspect

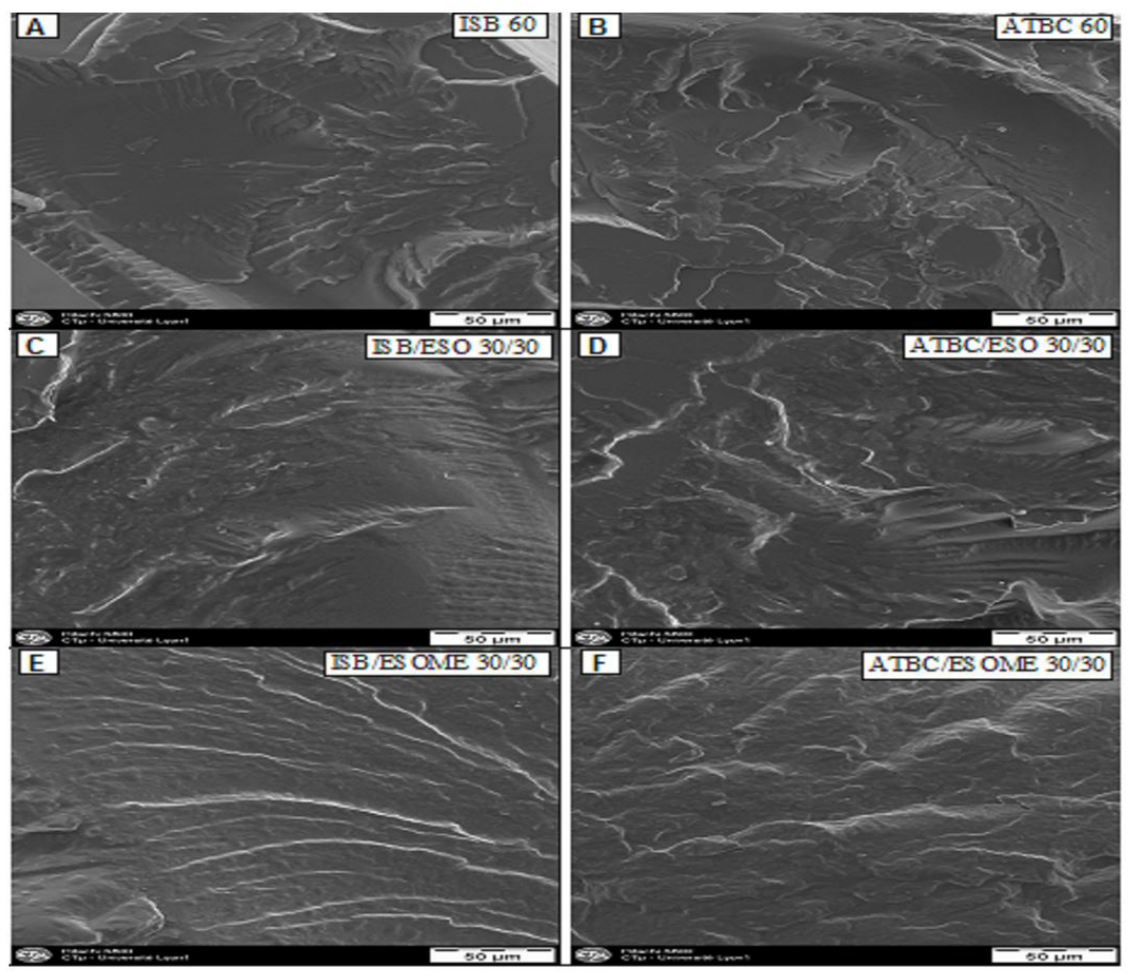

Figure 7. SEM micrographs of fracture surfaces of PVC films with different plasticizer compositions: (A) ISB 60 phr; (B) ATBC60 phr; (C) ISB/ESO 30/30; (D) ATBC/ESO 30/30; (E) ISB/ESOME 30/30; (F) ATBC/ESOME 30/30. 
has been obtained, without presence of PVC aggregates, when ISB or ATBC are used alone or with ESO and ESOME (30/30), which indicates a good miscibility between PVC and plasticizer systems, responsible for the higher levels of mechanical performances of films ${ }^{[34]}$. The obtained surfaces are rather homogeneous and smooth with little roughness.

This influence on the morphology of plasticized mixtures (with ISB, ATBC, ESO and ESOME) can be attributed to a decrease in the matrix viscosity and denotes a good dispersion of plasticizers in the PVC matrix ${ }^{[35]}$.

\section{Conclusions}

Discoloration change as well as thermal degradation decreases when increasing the amount of ESO or ESOME from 10 to $30 \mathrm{phr}$ in plasticized systems. The effect of the four plasticizers systems on the glass transition temperature of PVC is similar, lowering $\mathrm{Tg}$ from $81^{\circ} \mathrm{C}$ for unplasticized $\mathrm{PVC}$ to values in the range $\left[62^{\circ} \mathrm{C}, 65^{\circ} \mathrm{C}\right]$ for $\mathrm{PVC}$ specimens plasticized with different plasticizers systems. T $\alpha$ and FWHM decrease when increasing the amount of ISB or ATBC; which indicates they have a good compatibility with PVC. Tensile strength at break of PVC formulations with different plasticizers mixtures remains about constant by decreasing the ESO or ESOME level from 30 to $10 \mathrm{phr}$, the elongation at break is rather stable with ESO or ESOME levels from 20 to $10 \mathrm{phr}$.

The analysis of the morphology indicates that all the plasticizers have good compatibility with PVC.

ATBC or ISB with 10 to $30 \mathrm{phr}$ of ESO or ESOME are good candidates to substitute phthalates such as DEHP in flexible PVC formulations.

The use of secondary biobased plasticizers, such as ESO and ESOME with other primary biobased plasticizers as ISB and ATBC is a good way for the production of flexible PVC with low health toxicity and low environmental impacts.

\section{References}

1. García-Quesada, J. C., Marcilla,A., \& Gilbert, M. (2001). Study of the pyrolysis behaviour of peroxide crosslinked unplasticized PVC. Journal of Analytical and Applied Pyrolysis, 58-59, 651666. http://dx.doi.org/10.1016/S0165-2370(00)00195-9.

2. Zhang, K. H., Cao, W. L., Zhang, J. C. (2004) Solid-phase photocatalytic degradation of PVC by Tungstophosphoric acid - a novel method for PVC plastic degradation. Applied Catalysis A: General, 276(1-2), 67-73. http://dx.doi.org/10.1016/j. molcata.2006.12.012.

3. Bhakti, M., Mukesh, K., \& Jitesh, M. (2014) Bio-based coplasticizer for PVC in Addition with epoxidised soyabean oil to replace phthalates. Journal of Engineering and Technology, 3(4), 20-30. Retrieved in 10 November 2016, from http:// http:// www.rroij.com/open-access/bio-based-co-plasticizer-for-pvcin-addition-with-epoxidised-soyabean-oil-to-replace-phthalates. php?aid=34499.

4. David, R. M., Moore, R. M., Finney, D. C., \& Guest, D. (2000). Chronic toxicity of di(2-ethylhexyl) phthalate in mice. Toxicological Sciences, 58(2), 377-385. PMid:11099649. http:// dx.doi.org/10.1093/toxsci/58.2.377.

5. Blystone, C. R., Kissling, G. E., Bishop, J. B., Chapin, R. E., Wolfe, G. W., \& Foster, P. M. D. (2010). Determination of the Di-(2-Ethylhexyl) phthalate NOAEL for reproductive development in the rat: importance of the retention of extra animals to adulthood. Toxicological Sciences, 116(2), 640-646. http://dx.doi.org/10.1093/toxsci/kfq147.

6. Swan, S. H. (2008). Environmental phthalate exposure in relation to reproductive outcomes and other health endpoints in humans. Environmental Research, 108(2), 177-184. PMid:18949837. http://dx.doi.org/10.1016/j.envres.2008.08.007.

7. Mao, D., Chaudhary, B. I., Sun, B., Shen, C.-Y., Yuan, D., Dai, G. C., Li, B., \& Cogen, J. M. (2015). Absorption and migration of bio-based epoxidized soybean oil and its mixtures with tri(2-ethylhexyl) trimellitate in poly(vinylchloride). Journal of Applied Polymer Science, 132(19), 41966-41972. http:// dx.doi.org/10.1002/app.41966.

8. Jia, P., Bo, C., Hu, L., Zhang, M., \& Zhou, Y. (2016). Synthesis of a novel polyester plasticizer based on glyceryl monooleate and its application in poly (vinyl chloride). Journal of Vinyl Additive and Technology, 22(4), 514-519. http://dx.doi. org/10.1002/vnl.21468.

9. Bouchareb, B., \& Benaniba, M. T. (2008). Effects of epoxidized sunflower oil on the mechanical and dynamical analysis of the plasticized poly (vinyl chloride). Journal of Applied Polymer Science, 107(6), 3442-3450. http://dx.doi.org/10.1002/app.27458.

10. Benaniba, M. T., \& Massardier-Nageotte, V. (2010). Evaluation effects of biobased plasticizer on the thermal, mechanical, dynamical mechanical properties, and permanence of plasticized PVC. Journal of Applied Polymer Science, 118(6), 3499-3508. http://dx.doi.org/10.1002/app.32713.

11. Krauskopf, L. G. (1999). Prediction of plasticizer solvency using hansen solubility parameters. Journal of Vinyl Additive and Technology, 5(2), 101-106. http://dx.doi.org/10.1002/ vnl.10316.

12. Martin, T. M., \& Young, D. M. (2003). Correlation of the glass transition temperature of plasticized PVC using a lattice fluid model. Polymers, 44(16), 4747-4754. http://dx.doi.org/10.1016/ S0032-3861(03)00446-4.

13. Bouchoul, B., Benaniba, M. T., \& Massardier, V. (2014). Effect of biobased plasticizers on thermal, mechanical, and Permanence Properties of Poly(vinyl chloride). Journal of Vinyl and Additive Technology, 20(4), 260-267. http://dx.doi. org/10.1002/vnl.21356.

14. Gil, N., Saska, M. \& Negulescu, I., \& (2006). Evaluation of the effects of biobased plasticizers on the thermal and mechanical properties of poly(vinyl chloride). Journal of Applied Polymer Science, 102(2), 1366-1373. http://dx.doi. org/10.1002/app.24132.

15. Meyer, P., Techaphattana, N., Manundawee, S., Sangkeaw, S., Junlakan, W., \& Tongurai, C. (2008). Epoxidation of soybean oil and jatropha oil. Thammasat International Journal of Sciences and Technology, 13(Special edition), 1-5.

16. Americans Oil Chemists Society - AOCS. (1979). Sampling and analysis of commercial fats and oils: AOCS official method Cd 9.57. Urbana, IL: AOCS.

17. Holser, R. A. (2008). Transesterification of epoxidized soybean oil to prepare epoxy methyl esters. Industrial Crops and Products, 27(1), 130-132. http://dx.doi.org/10.1016/j. indcrop.2007.06.001.

18. Ocskay, G., Nyitrai, Z., Várfalvi, F., \& Wein, T. (1971). Investigation of degradation processes in PVC based on the concomitant colour changes. European Polymer Journal, 7(8), 1135-1145. http://dx.doi.org/10.1016/0014-3057(71)90146-7.

19. Gan, L. H., Goh, S. H., \& Ooi, K. S. (1992). Kinetic studies of epoxidation and oxirane cleavage of palm olein methyl esters. Journal of the American Oil Chemists'Society, 69(4), 347-351. http://dx.doi.org/10.1007/BF02636065. 
20. Purwanto, E. (2010). The synthesis of polyols from RBO through epoxidation and hydroxylation reactions (Master's thesis). University of Adelaide, Adelaide.

21. Schuchardt, U., Sercheli, R., \& Vargas, R. M. (1998). Transesterification of vegetable oils: a review. Journal of the Brazilian Chemical Society, 9(3), 199-210. http://dx.doi. org/10.1590/S0103-50531998000300002.

22. Nihul, P. G., Mhaske, S. T., \& Shertukde, V. V. (2014). Epoxidized rice bran oil (ERBO) as a plasticizer for poly (vinyl chloride) (PVC). Iranian Polymer Journal, 23(8), 599-608. http://dx.doi. org/10.1007/s13726-014-0254-7.

23. Sammaiah, A., Padmaja, K. V., \& Prasad, R. B. N. (2014). Synthesis of epoxy jatropha oil and its evaluation for lubricant properties. Journal of Oleo Science, 63(6), 637-643. PMid:24829128. http://dx.doi.org/10.5650/jos.ess13172.

24. Waskitoaji, W., Triwulandari, E., \& Haryono, A. (2012). Synthesis of plasticizers derived from palm oil and their application in polyvinyl chloride. Procedia Chemistry, 4(1), 313-321. http://dx.doi.org/10.1016/j.proche.2012.06.044.

25. Sun, B., Chaudhary, B. I., Shen, C. Y., Mao, D., Yuan, D. M., Dai, G. C., Li, B., \& Cogen, J. M. (2013). Thermal stability of epoxidized soybean oil and its absorption and migration in poly(vinylchloride). Polymer Engineering and Science, 53(8), 1645-1656. http://dx.doi.org/10.1002/pen.23417.

26. Bueno-Ferrer, C., Garrigós, M. C., \& Jiménez, A. (2010). Characterization and thermal stability of poly (vinyl chloride) plasticized with epoxidized soybean oil for food packaging. Polymer Degradation \& Stability, 95(11), 2207-2212. http:// dx.doi.org/10.1016/j.polymdegradstab.2010.01.027.

27. Gamage, P. K., Farid, A. S., \& Karunanayake, L. (2009). Kinetics of degradation of PVC-containing novel neem oil as stabilizer. Journal of Applied Polymer Science, 112(4), 2151-2165. http://dx.doi.org/10.1002/app.29686.

28. Joseph, R., Madhusoodhanan, K. N., Alex, R., Varghese, S., George, K. E., \& Kuriakose, B. (2004). Studies on epoxidised rubber seed oil as secondary plasticiser/stabiliser for polyvinyl chloride. Plastics, Rubber and Composites, 33(5), 217-222. http://dx.doi.org/10.1179/146580104225020974.
29. Stuart, A., Le Captain, D. J., Lee, C. Y., \& Mohanty, D. K. (2013). Poly(vinyl chloride) plasticized with mixtures of succinate di-esters - synthesis and characterization. European Polymer Journal, 49(9), 2785-2791. http://dx.doi.org/10.1016/j. eurpolymj. 2013.06.023.

30. Cadogan, D. F. (1991). Plasticizers: a consideration of their impact on health and the environment. Journal of Vinyl and Additive Technology, 13(2), 104-108. http://dx.doi.org/10.1002/ vnl.730130209.

31. Ghiou, N., \& Benaniba, M. T. (2010). The effect of epoxidized sunflower oil on the miscibility of plasticized PVC/NBR blends. International Journal of Polymeric Materials, 59(7), 463-474. http://dx.doi.org/10.1080/00914031003627007.

32. Shah, B. L., \& Shertukde, V. V. (2003). Effect of plasticizers on mechanical, electrical, permanence, and Thermal Properties of Poly (vinyl chloride). Journal of Applied Polymer Science, 90(12), 3278-3284. http://dx.doi.org/10.1002/app.13049.

33. Chaudhary, B. I., Nguyen, B. D., Smith, P., Sunday, N., Luong, M., \& Zamanskiy, A. (2015). Bis(2-ethylhexyl) succinate in mixtures with epoxidized soybean oil as bio-based plasticizers for poly(vinylchloride). Polymer Engineering and Science, 55(3), 634-640. http://dx.doi.org/10.1002/pen.23934.

34. Fenollar, O., Garcia-Sanoguera, D., Sanchez-Nacher, L., Boronat, T., López, J., \& Balart, R. (2013). Mechanical and thermal properties of polyvinyl chloride plasticized with natural fatty acid esters. Polymer-Plastics Technology and Engineering, 52(8), 761-767. http://dx.doi.org/10.1080/036 02559.2013 .763352 .

35. Yu, Z., Zhou, J., Zhang, J., Huang, K., Cao, F., \& Wei, P. (2014). Evaluating effects of biobased 2,5-furandicarboxylate esters as plasticizers on the thermal and mechanical properties of poly (vinyl chloride). Journal of Applied Polymer Science, 131(20), 40938-40948. http://dx.doi.org/10.1002/app.40938.

Received: Nov. 10, 2016

Revised: Jan. 05, 2017

Accepted: Mar. 02, 2017 